would wish to have a sound and fundamental grasp of his subject, because, however wide his reading of current literature may have been, he will find in this book some knowledge which would otherwise have escaped him. The book is more than this, however, because the production, in the midst of a world war, of a treatise so detailed, learned and eminently readable, is an indication of how well the spirit of this island can react to the noxious stimuli of Nazi aggressiveness.

We are sure that all English-speaking ophthalmologists will be proud of this latest edition to their literature and will wish to congratulate the author on his achievement.

\title{
CORRESPONDENCE
}

\section{CYCLODIATHERMY PUNCTURE IN GLAUCOMA}

To the Editors of THE BRITISH JOURNAL OF OPHTHALMOLOGy.

DEAR SIRS,- - Your issue of June last contains a translation of a paper by Dr. A. Vogt on cyclodiathermy puncture in cases of glaucoma. He bases a strong recommendation of this procedure on an experience of "hundreds" of observations extending over a period of three years.

In his enthusiastic advocacy of C.D.P. he contrasts its freedom from dangerous sequelae with the liability of the sub-conjunctival filtration methods (the decompressions), to these complications.

According to Vogt "sympathetic ophthalmitis has so far never been observed after C.D.P." but is "especially frequent after trephining and iris inclusion."

Readers can place their own eclectic value on the first part of this statement, it obviously needs augmentation and confirmation by other observers, if it is to have any statistical scientific importance.

The second assertion quoted, however unfortunate Vogt's personal experience may be, can hardly be accepted as fair criticism of "all those methods with sub-conjunctival filtration."

In an experience of over 3,500 decompressions, composed of cases operated on by me and my former colleague, Dr. Koman Nayar or associates and visiting ophthalmologists under our supervision, extending over a period of 18 years ending April 1937, there was not a single instance of sympathetic ophthalmia. Nor have I come across a case of sympathetic ophthalmia in decompressions performed by my predecessors at the Madras Clinic, many of 
whose patients I was enabled to inspect, nor in my private practice which would raise the figure given by several hundreds.

In a communication on sympathetic ophthalmia, one of a series presented by the Staff of the Government Ophthalmic Hospital, Madras, Koman Nayar gives the figure 0.003 per cent. as the rate of occurrence in all eye cases attending the Madras Clinic over the period of 15 years ending 1935. (Proc. All Ind. Oph. Soc., Vol. IV, 1935.)

My own exceedingly limited experience of C.D.P. as performed by others is distressing, but it would be unfair to infer from this that it may not find a useful place amongst the various operative methods of dealing with abnormal intra-ocular tension. I should be very sorry to employ C.D.P. experimentally on high tension eyes, other than those which were already blind, without first observing a consecutive series of operations by Vogt and following them up for a reasonable time.

It would be quite justifiable and relatively easy for observers in India to repeat Vogt's C.D.P. work on eyes blind of chronic glaucoma in which a lowering of tension is indicated.

Yours truly,

ENGLAND.

ROBERT E. WRIGHT.

To the Editors of THE BRITISH JOURnal OF OPHTHaLMOLOGY.

DEAR SIRS,-Especial emphasis is, I consider, desirable upon one matter to which reference is made in the interesting paper by Savin and Tyrrell in the November number of the Journal.

Comment No. 7 on p. 564 is as follows:- "If proctocaine is employed for the relief of pain in a blind eye, all possibility of neoplasm should be excluded (see case $n$ )." Case $n$ referred to a patient who had refused enucleation that had been very wisely recommended in the belief that the glaucoma was due to central vein thrombosis.

In 1925 I reported upon 402 consecutive cases of blind painful eyes that had been excised at Moorfields Eye Hospital during a period of two to three years." The word "blind" was used to denote "almost blind, and useless." In two of this series an operation had been performed in the hope of saving the eye. Fortunately the wound of operation-for iridectomy-failed to heal, and the eye was in each case enucleated a few days later. Each of these eyes as well as 14 others, i.e., 4 per cent.. contained a sarcoma of the choroid. In a considerable proportion of such cases, owing to corneal haze the result of increased tension, or to secondary or senile cataract, the interior of the eye cannot be examined. 